J. Clin. Chem. Clin. Biochem.

Vol. 26, 1988, pp. 259-264

(C) 1988 Walter de Gruyter \& Co. Berlin - New York

\title{
Urinary Glycosaminoglycans in Patients with Hypothyroidism and in Healthy Subjects
}

\author{
By Hanna Wlad, W. Fenrych \\ Department of Biochemistry, University School of Medicine, Poznań, Poland
}

Katarzyna Lacka and Wanda Sikorska-Horst

Department of Endocrinology, University School of Medicine, Poznań, Poland

(Received November 18, 1986/July 13, 1987/February 9, 1988)

Summary: Although the changes in urinary glycosaminoglycans have been investigated in several endocrinopathies, no information was hitherto available on the content and composition of urinary glycosaminoglycans in hypothyroidism. Urinary glycosaminoglycans were therefore investigated in patients with hypothyroidism and in healthy subjects. The total daily excretion of urinary glycosaminoglycans was found to be significantly increased (by $41 \%$ ) in hypothyroidism. Two electrophoretic bands were always detected in both examined groups: a major band of chondroitin sulphate and a minor band of heparan sulphate. Heparan sulphate and chondroitin sulphate levels were respectively $114 \%$ and $42 \%$ higher in patients with hypothyroidism than in controls. The respective increases in chondroitin-4-sulphate and chondroitin-6-sulphate were $31 \%$ and $41 \%$. The relative quantities of chondroitin-4-sulphate, dermatan sulphate, chondroitin-6-sulphate and non-sulphated chondroitin sulphate were unchanged in the two examined groups. The changes observed in the levels of the excreted glycosaminoglycans may reflect the altered metabolism of connective tissue in hypothyroidism.

\section{Introduction}

Glycosaminoglycans are widely distributed in human tissues, reaching high concentration in connective tissue ground substance, synovial fluid, hyaline cartilage and cornea (1). Urinary glycosaminoglycans represent heterogenous mixture of partially depolymerized and partially desulphated products of tissue glycosaminoglycans. Most investigations indicate that urinary glycosaminoglycans originate from the plasma by glomerular filtration, although part of the heparan sulphate fraction may originate from renal tissue $(2,3)$. Because urinary glycosaminoglycans are derived from different types of connective tissue, studies of their excretion should provide information on the metabolic status of these tissues.

Glycosaminoglycan and proteoglycan metabolism is influenced by a number of hormones. The perturbations in glycosaminoglycan metabolism seen in association with thyroid disease were first characterized by Watson \& Pearce, who demonstrated that the mucinous dermal substance which accumulated in affected areas of a patient with localized pretibial myxoedema contained increased amounts of hyaluronic acid and chondroitin sulphates as compared with unaffected skin (4). In generalized myxoedema, which is due to hypothyroidism, an increase of hyaluronic acid and sulphated glycosaminoglycans was observed in the tissues. This is due to decreased catabolism of hyaluronic acid and an increased rate of synthesis of sulphated glycosaminoglycans $(5,6)$.

Because to our knowledge no studies have been reported on urinary glycosaminoglycans in patients with hypothyroidism, it was of interest to perform a comparative investigation on glycosaminoglycans in the urine of these subjects. The present paper reports the detailed quantitative and qualitative analysis of urinary glycosaminoglycans in patients with hypothyroidism. 


\section{Materials and Methods}

Patients ( $\mathrm{n}=23$, female) with hypothyroidism (average age $34 \pm 3$ years) were studied. All diagnoses were confirmed by the assay of thyroxine and triiodothyronine concentrations. These patients were not treated before urine collection and except for thyroid dysfunction they had no other diseases. Reference samples $(n=20)$ were obtained from adult females (average age $33 \pm 7$ years) free from acute illness and without history of chronic disease.

Whole $24 \mathrm{~h}$ urine was collected with thymol crystals as a preservative. Creatinine was measured in all samples by the method of Folin (7). Only those $24 \mathrm{~h}$ urines which gave creatinine values within the normal range were accepted.

\section{Chemicals}

Chrondroitin AC lyase (EC 4.2.2.5), chondroitin ABC lyase (EC 4.2.2.4), chondro-6-sulphatase (EC 3.1.6.10), chondro-4sulphatase (EC 3.1.6.9), the unsaturated disaccharides as well as standard chondroitin 4-sulphate from whale cartilage were from Seikagaku Kogyo Co, Tokyo.

Standard chondroitin 6-sulphate (from shark cartilage) and dermatan sulphate (from pig skin) were from Miles Laboratories.

Standard heparan sulphate from beef lung was a gift from Prof. A. L. Horwitz, Dept. of Pediatrics, University of Chicago (this is a standard prepared in the laboratory of Dr M.B. Mathew's and $\operatorname{Dr} J$. A. Cifonelli, University of Chicago (8)).

Standard hyaluronic acid from human umbilical cord, heparin, testicular hyaluronidase, heparitinase and Trizma base were from Sigma.

Cellulose acetate strips (cellogel) and dialysis tubes were a product of Serva.

Pronase (specific activity 56300 proteolytic units/g) was from Calbiochem.

Alcian blue $8 \mathrm{GX}$ was from Windsor Lab. Ltd., Slough, Berkshire U.K.

Cetylpyridinium chloride and chondroitin sulphate ex shark were from Koch-Light Laboratories LTD.

\section{Isolation of glycosaminoglycans from urine}

The urine specimens were centrifuged at $3000 \mathrm{~g}$ for $15 \mathrm{~min}$ and adjusted to $\mathrm{pH} 5.0$ with acetic acid. By the addition of $0.4 \mathrm{ml}$ of $50 \mathrm{~g} / \mathrm{l}$ cetylpyridinium chloride per $20 \mathrm{ml}$ of urine, glycosaminoglycans were precipitated as cetylpiridinium chloride polysaccharide complex at $4{ }^{\circ} \mathrm{C}$ overnight. The resulting precipitate was washed twice with ethanol saturated with $\mathrm{NaCl}$, once with ether then dried. The precipitate was dissolved in $4 \mathrm{ml} 0.6$ $\mathrm{mol} / \mathrm{l} \mathrm{NaCl}$ and left for one hour in an iced water bath. Insoluble material was removed by centrifugation, and the glycosaminoglycans were precipitated from the supernatant by the addition of $4 \mathrm{vol}$ of absolute ethanol at $4{ }^{\circ} \mathrm{C}$ for $12 \mathrm{~h}$. The precipitate was collected, washed successively with absolute ethanol and ether and dried in air. The precipitate was dissolved in $1 \mathrm{ml}$ of $0.1 \mathrm{~mol} / 1$ Tris $-\mathrm{HCl}$ buffer $(\mathrm{pH} \mathrm{7.8)}$ containing $5 \mathrm{mmol}$ $\mathrm{CaCl}_{2}$ and $0.1 \mathrm{~g} / \mathrm{l}$ thymol and the solution was diluted with the same volume of water. The diluted solution was heated in a boiling water bath for $30 \mathrm{~min}$, followed by cooling to $50^{\circ} \mathrm{C}$, then incubated with pronase for two days at $50^{\circ} \mathrm{C}(0.5 \mathrm{mg}$ pronase was added on each day of incubation). After cooling the digest to $4^{\circ} \mathrm{C}$, trichloroacetic acid $(300 \mathrm{~g} / \mathrm{l})$ was added to give a final concentration of $100 \mathrm{~g} / \mathrm{l}$. The mixture was left to stand for $4 \mathrm{~h}$ at $4^{\circ} \mathrm{C}$ then centrifuged at $8000 \mathrm{~g}$ for $15 \mathrm{~min}$ at $4^{\circ} \mathrm{C}$. Glycosaminoglycans were precipitated from the super- natant by the addition of $4 \mathrm{vol}$ of ethanol saturated with sodium acetate at $4^{\circ} \mathrm{C}$ for $12 \mathrm{~h}$. The last procedure was repeated twice, then the precipitate, consisting of crude glycosaminoglycans, was washed with absolute ethanol and ether and dried in vacuo over $\mathrm{P}_{2} \mathrm{O}_{5}$.

\section{Recovery of chondroitin sulphate added to urine}

Various amounts of commercial chondroitin sulphate were added to urine. The isolation and purification of glycosaminoglycans were performed as described before. Uronic acid was determined by the carbazole method of Bitter \& Muir (9).

\section{Electrophoresis on cellulose acetate membrane}

Two dimentsional electrophoresis on Cellogel membrane was performed according to Mossman \& Patrick (10), using pyridine/acetic acid/water $(10+1+89$, by vol; $\mathrm{pH} 6.0)$ for 60 min in the first dimension and $0.1 \mathrm{~mol} / 1$ barium acetate $\mathrm{pH} 7.7$ for $130 \mathrm{~min}$ in the second dimension, both with an applied potential $7.5 \mathrm{~V} / \mathrm{cm}$. The strip was then stained with Alcian blue in methanol/acetic acid/water $(50+5+45$, by vol.), destained with $0.9 \mathrm{~mol} / \mathrm{l}$ acetic acid and further washed with water. Glycosaminoglycans were identified by comparing their electrophoretic mobilities with those of the standard.

\section{Enzymatic analysis}

The further identification of urinary glycosaminoglycans was based on degradation with testicular hyaluronidase, heparitinase and chondroitinases $\mathrm{AC}$ and $\mathrm{ABC} \mathrm{C}^{\prime}$ ). Glycosaminoglycans isolated from $40 \mathrm{ml}$ of urine were dissolved in $200 \mu \mathrm{l}$ of distilled water. $50 \mu \mathrm{l}$ of this solution was digested with chondroitinase $\mathrm{ABC}(0.08$ unit/20 $\mu$ l of Tris $\mathrm{HCl}$ buffer), $50 \mu$ with chondroitinase $\mathrm{AC}(0.12$ unit/20 $\mu \mathrm{l}$ of Tris $\mathrm{HCl}$ buffer), $50 \mu \mathrm{l}$ with heparitinase $(0.1$ unit/ $20 \mu \mathrm{l}$ of sodium acetate buffer) and $50 \mu \mathrm{l}$ with testicular hyaluronidase $(100 \mu \mathrm{g} / 20 \mu \mathrm{l}$ of sodium acetate buffer). Digestion with chondroitinases was carried out in 50 $\mathrm{mmol} / \mathrm{l}$ Tris $\mathrm{HCl}$ buffer $(\mathrm{pH} 8.0)$ at $37^{\circ} \mathrm{C}$ for $2 \mathrm{~h}$ (11). Digestion with heparitinase was performed in $0.2 \mathrm{~mol} / 1$ sodium acetate buffer (pH 7.0) at $37^{\circ} \mathrm{C}$ for $12 \mathrm{~h}(12,13)$. Digestion with bovine testicular hyaluronidase was carried out by using $0.1 \mathrm{~mol} / \mathrm{l}$ sodium acetate buffer ( $\mathrm{pH} 5.0$ ) containing $0.15 \mathrm{~mol}$ sodium chloride, for $24 \mathrm{~h}$ at $37^{\circ} \mathrm{C}(14)$. Following the enzyme digestion the reaction mixtures were deproteinized with trichloroacetic acid (final $100 \mathrm{~g} / \mathrm{l}$ ), the resulting precipitate was removed by centrifugation and the supernatants were dialysed against distilled water overnight in the cold and lyophilized. The lyophilized material was analysed for glycosaminoglycans by two dimensional electrophoresis as previously described. The specificity of enzymes used was examined by digestion and electrophoresis of standard glycosaminoglycans.

\section{Other analytical methods}

Quantification of glycosaminoglycans separated on cellulose acetate was carried out according to the procedure of Hronowski et al. (15). The uronic acid content was determined by two methods: the orcinol method of Brown (16) and the carbazole method of Bitter \& Muir (9). The hexosamine content was determined by the method of Blumenkrantz \& Asboe-Hansen (17) after hydrolysis of the specimen in $4 \mathrm{~mol} / \mathrm{l} \mathrm{HCl}$ for $11 \mathrm{~h}$ at $100^{\circ} \mathrm{C}$. Glucosamine and galactosamine were estimated sepa-

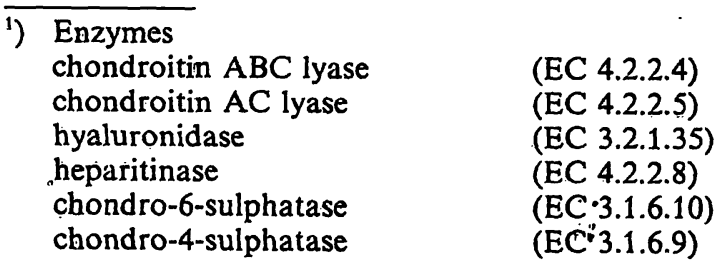


rately by Wagner's modification (18) of the method reported by Blumenkrantz \& Asboe-Hansen (17), using an acid hydrolysate.

Isomeric chondroitin sulphates, which could not be estimated by electrophoresis, were determined by the enzymatic method reported by Saito et al. (11) and Murata et al. (19). Glycosaminoglycans isolated from $20 \mathrm{ml}$ of urine were dissolved in 100 $\mu l$ of distilled water and $10 \mu l$ of this solution was added to each reaction tube (tab. 1). All reaction mixtures were incubated for $60 \mathrm{~min}$ at $37^{\circ} \mathrm{C}$. The resulting unsaturated disaccharides were detcrmined with the Morgan-Elson reaction and quantified as described by Saito et al. in method II with a reference mixture (11).

\section{Results}

Several methods reported by different authors $(20$, 21,22 ) were assessed for the isolation of pure glycosaminoglycans from urine. After these experiments, one combined method of isolation was chosen. The mean recovery of chondroitin sulphate added was 93.8 $\pm 9.8 \%$. Urinary glycosaminoglycans isolated from healthy subjects and from hypothyroidism patients were separated into two fractions by two dimensional electrophoresis. The main fraction corresponded in mobility to standard chondroitin-4/6-sulphate and dermatan sulphate, and was susceptible to treatment with testicular hyaluronidase, chondroitinase $A B C$ and chondroitinase AC. Treatment with these enzymes resulted in complete disapperance of the band. This fraction was not susceptible to digestion with heparitinase. The minor band migrated like standard heparan sulphate; it was not susceptible to digestion with testicular hyaluronidase and chondroitinases, but it was susceptible to heparitinase, which caused the band to split. Figure 1 shows typical patterns of
Tab. 1. Preparation of reaction mixtures for determination of isomeric chondroitin sulphates

\begin{tabular}{|c|c|c|c|c|c|}
\hline Number of tube & 1 & 2 & 3 & 4 & blank \\
\hline Reagents & \multicolumn{5}{|c|}{ Volume added (in $\mu \mathrm{l}$ ) } \\
\hline $\mathrm{H}_{2} \mathrm{O}$ & 30 & 10 & 15 & 40 & 50 \\
\hline Tris $\mathrm{HCl}$ buffer $\mathrm{pH} 8.0$ & 15 & 15 & 15 & 15 & 15 \\
\hline $\begin{array}{l}\text { Chondroitinase } A B C \\
(2000 \text { units/l) }\end{array}$ & 10 & - & 10 & 10 & - \\
\hline $\begin{array}{l}\text { Chondroitinase } \mathrm{AC} \\
(4000 \text { units } / 1)\end{array}$ & - & 15 & - & - & - \\
\hline $\begin{array}{l}\text { Chondro-6-sulphatase') } \\
(670 \text { units/1) }\end{array}$ & - & 15 & 15 & - & - \\
\hline $\begin{array}{l}\text { Chondro-4-sulphatase') } \\
(1000 \text { units/l) }\end{array}$ & 10 & 10 & 10 & - & - \\
\hline Urine sample & 10 & 10 & 10 & 10 & 10 \\
\hline
\end{tabular}

urinary glycosaminoglycans isolated from healthy subjects (fig. $1 \mathrm{a}$ ) and from hypothyroidism patients (fig. $1 \mathrm{~b}$ ), as well as the separation of six reference glycosaminoglycan standards (fig. $1 \mathrm{c}$ ) obtained by two dimensional electrophoresis on cellulose acetate membranes. Total glycosaminoglycans in urine (expressed as uronic acid) was determined by three methods: the carbazole method of Bitter \& Muir, the orcinol method of Brown, and determination after two dimensional electrophoretic separation according to Hronowski. The results of these experiments are shown in table 2 and table 3 . The total daily excretion of glycosaminoglycans, measured by the carbazole method was $41 \%$ higher in hypothyroidism than in a control group. Very similar differentiation was found using the two other methods. Hexosamine analysis of urinary glycosaminoglycans indicated that changes in total content of hexosamine in pathologic specimens $\oplus$

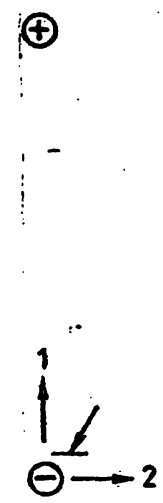

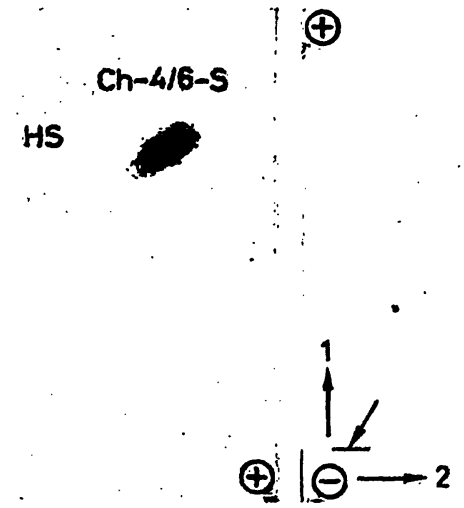

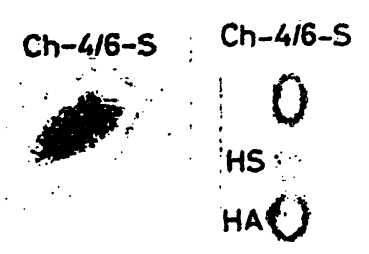

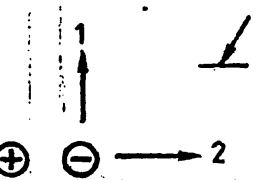

HS DS Ch-4/6-S

$O$

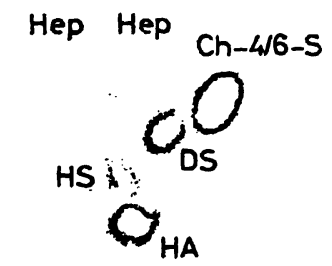

Fig. 1. Two dimensional electrophoresis patterns of urinary glycosaminoglycans of healthy females (a), patients with hypothyroidism (b) and an authentic sample composed of chondroitin-4-sulphate (Ch-4-S), chondroitin-6-sulphate (Ch-6-S), dermatan sulphate (DS), hyaluronic acid (HA), heparan sulphate (HS) and heparin (Hep) - $2.0 \mu \mathrm{g}$ of each (c). Reference glycosaminoglycan standards for the run in the first dimension are chondroitin-4/6-sulphate (the fastest), heparan sulphate and hyaluronic acid (the slowest) and in the second dimension chondroitin-4/6-sulphate (the fastest), dermatan sulphate and heparan sulphate (the slowest). Conditions for electrophorcsis and staining as described under Materials and Methods. Migration directions are marked with large arrows. Small arrow indicates the application point of the samples. 
Tab. 2. Total urinary glycosaminoglycan content (expressed as uronic acid and hexosamine content) in patients with hypothyroidism and in healthy individuals (mean \pm SD)

\begin{tabular}{|c|c|c|c|}
\hline & $\begin{array}{l}\text { Hypothyroidism } \\
{ }^{\mathrm{a}} \mathrm{N}=19\end{array}$ & $\begin{array}{l}\text { Healthy control } \\
{ }^{\mathrm{a}} \mathrm{N}=20\end{array}$ & Statistical $^{b}$ analysis \\
\hline $\begin{array}{l}\text { Uronic acid measured by carbazole method } \\
(\mu \mathrm{mol} / 24 \mathrm{~h}) \\
\mathrm{mg} / \mathrm{g} \text { of creatinine }\end{array}$ & $\begin{array}{r}18.96 \pm 6.18 \\
3.20 \pm 1.04\end{array}$ & $\begin{array}{r}13.39 \pm 1.80 \\
2.26 \pm 0.30\end{array}$ & $\mathrm{t}_{\mathrm{c}}^{\prime}=3.7>\mathrm{t}_{\mathrm{t}}=2.1$ \\
\hline $\begin{array}{l}\text { Uronic acid measured by orcinol method } \\
(\mu \mathrm{mol} / 24 \mathrm{~h}) \\
\text { Hexosamine }(\text { total })(\mu \mathrm{mol} / 24 \mathrm{~h}) \\
\text { Glucosamine }(\mu \mathrm{mol} / 24 \mathrm{~h}) \\
\text { Galactosamine }(\mu \mathrm{mol} / 24 \mathrm{~h})\end{array}$ & $\begin{array}{r}19.11 \pm 5.67 \\
24.11 \pm 8.50 \\
4.25 \pm 1.27 \\
19.86 \pm 7.36\end{array}$ & $\begin{array}{r}13.24 \pm 2.16 \\
16.81 \pm 2.66 \\
3.04 \pm 0.51 \\
13.77 \pm 2.22\end{array}$ & $\begin{array}{l}\mathrm{t}_{\mathrm{c}}=4.1>\mathrm{t}_{\mathrm{t}}=2.1 \\
\mathrm{t}_{\mathrm{c}}=3.5>\mathrm{t}_{\mathrm{t}}=2.1 \\
\mathrm{t}_{\mathrm{c}}=3.4>\mathrm{t}_{\mathrm{t}}=2.1 \\
\mathrm{t}_{\mathrm{s}}=4.0>\mathrm{t}_{\mathrm{T}}=2.0\end{array}$ \\
\hline
\end{tabular}

$\mathrm{N}$ - number of cases

- For the comparison of the mean values in two populations Fischer's test was primarily used. When Fischer's test indicated significant differences between variances, the Cohran-Cox test $\left(t_{c}, t_{t}\right)$ was used. In other case Student's $t$ test $\left(t_{s}, t_{T}\right)$ was applied. The level $p=0.05$ was regarded as significant.

Tab. 3. Electrophoretic analysis of urinary glycosaminoglycans in patients with hypothyroidism and in healthy individuals (mean $\pm \mathrm{SD})$

\begin{tabular}{|c|c|c|c|c|}
\hline \multirow[b]{2}{*}{$\ddots_{i}$} & \multirow{2}{*}{$\begin{array}{l}\text { No. of } \\
\text { cases }\end{array}$} & \multicolumn{3}{|c|}{ Glycosaminoglycans } \\
\hline & & Total & Heparan sulphate & Chondroitin-4/6-sulphate \\
\hline Healthy control & 20 & $\begin{array}{l}12.16 \pm 1.65^{a} \\
(100)_{b}\end{array}$ & $\begin{array}{l}2.01 \pm 0.36 \\
(17)\end{array}$ & $\begin{array}{l}10.15 \pm 1.45 \\
(83)\end{array}$ \\
\hline Hypothyroidism patients & 18 & $\begin{array}{l}17.15 \pm 4.94 \\
(100)\end{array}$ & $\begin{array}{l}2.73 \pm 0.72 \\
(16)\end{array}$ & $\begin{array}{l}14.42 \pm 4.53 \\
(84)\end{array}$ \\
\hline
\end{tabular}

a The mean values are expressed as uronic acids $(\mu \mathrm{mol} / 24 \mathrm{~h})$

b Numbers in parentheses indicate the percentage of total glycosaminoglycans

were comparable to the changes in their uronic acid content. In hypothyroidism a significant increase (by $43 \%$ ) of the total hexosamine level was observed. Galactosamine and glucosamine contents were increased by $45 \%$ and by $39 \%$, respectively (tab. 2). Glucosamine amounted $18 \%$ of total hexosamine in healthy subjects and $17 \%$ in hypothyroidism patients. The molar ratio of uronic acid/hexosamine was about 0.9 and was the same in the two examined groups.

In addition to the analysis of total uronic acids and hexosamine, individual glycosaminoglycan fractions were quantitated after two dimensional electrophoresis. The results of these experiments are shown in table 3.

Neither the two dimensional nor the one dimensional electrophoresis separates chondroitin sulphate isomers. These isomers were therefore quantitated enzymatically according to the method of Saito \& Murata. During treatment with chondroitinases and chondrosulphatases, urinary chondroitin sulphates in both examined groups of women were separated into unsaturated 4-sulphated, 6-sulphated and non sulphated disaccharides, which were then quantitated.
The amounts of chondroitin sulphate isomers measured as unsaturated disaccharides are summarized in table 4.

Tab. 4. Quantitative analysis of chondroitin sulfate isomers from the urinary glycosaminoglycans in patients with hypothyroidism and healthy subjects (mean $\pm \mathrm{SD}$ )

\begin{tabular}{|c|c|c|}
\hline $\begin{array}{l}\text { Chondroitin sulphate } \\
\text { isomers }\end{array}$ & $\begin{array}{l}\text { Healthy } \\
\text { control } \\
{ }^{2} \mathrm{~N}=17\end{array}$ & $\begin{array}{l}\text { Hypothyroidism } \\
\text { patients } \\
{ }^{\mathrm{a}} \mathrm{N}=19\end{array}$ \\
\hline Total & $\begin{array}{l}b_{11.48} \pm 2.06 \\
c^{c}(100)\end{array}$ & $\begin{array}{l}15.35 \pm 5.80 \\
(100)\end{array}$ \\
\hline Chondroitin-4-sulphate & $\begin{array}{l}7.42 \pm 1.24 \\
(64)\end{array}$ & $\begin{array}{l}9.70 \pm 3.75 \\
(63)\end{array}$ \\
\hline Dermatan sulphate & $\underset{(2)}{0.20} \pm 0.20$ & $\begin{array}{c}0.24 \\
(1)\end{array}$ \\
\hline Chondroitin-6-sulphate & $\begin{array}{l}3.22 \\
(28)\end{array} \pm 0.88$ & $\begin{array}{l}4.55 \pm 1.85 \\
(30)\end{array}$ \\
\hline $\begin{array}{l}\text { Non sulphated chondroitin } \\
\text { sulphate }\end{array}$ & $\begin{array}{c}0.64 \\
(6)\end{array} 0.31$ & $\begin{array}{l}0.86 \pm 0.36 \\
(6)\end{array}$ \\
\hline
\end{tabular}

a $\mathrm{N}$ - number of cases

b The mean values are expressed as uronic acids ( $\mu \mathrm{mol} / 24 \mathrm{~h}$ )

c Numbers in parentheses indicate the percentage of the total chondroitin sulphate isomers 


\section{Discussion}

Results obtained by different authors concerning the content and composition of urinary glycosaminoglycans in healthy subjects are not consistent. Since urinary glycosaminoglycan excretion is age- and sexdependent $(23,24)$, we chose for our study women in a narrow age group. In the present work urinary glycosaminoglycans were isolated using a combined method. Electrophoretic analysis of urinary glycosaminoglycan preparations obtained by the described procedure reveals a practically pure preparation without any significant glycoprotein contamination. The results of the current study, using electrophoretic analysis together with enzymatic hydrolysis, glucosamine and galactosamine analysis and determination of the carbazole/orcinol ratio, indicated that the main urine glycosaminoglycan is chondroitin sulphate and the minor one is heparan sulphate. The electrophoretic patterns suggest that part of the main urine glycosaminoglycan fraction might be dermatan sulphate. However, digestion with testicular hyaluronidase and with chondroitinases, as well as the fact that no appreciable increase of 4-sulphated to 6-sulphated disaccharides was found in the degraded products with chondroitinase $A B C$ over those degraded with chondroitinase $\mathrm{AC}$, indicated that there are only small amounts of dermatan sulphate in both hypothyroidism and control urine samples of glycosaminoglycan (tab. 4). These findings suggest that the main urine glycosaminoglycan fraction is largely composed of a chondroitin-4/6-sulphate type polymer, probably with low sulphate content. Urinary glycosaminoglycans may be undersulphated and thus migrate more slowly than marker samples derived from tissues (25). The determined composition of urinary glycosaminoglycan is in agreement with the findings of Yokoi (26), Goldberg (27) and Nanto-Salonen (28). The mean concentration of $24 \mathrm{~h}$ urine glycosaminoglycans from healthy subjects (measured as their uronic acid content by the carbazole method) was concluded in this study to be $2.26 \pm 0.30 \mathrm{mg} / \mathrm{g}$ creatinine $(13.39 \pm 1.80$ $\mu \mathrm{mol} / 24 \mathrm{~h})$. The yield obtained agrees with those reported by Varma (29), Murata (13) and Bowness (30). The borate-carbazole method gives" a low value for dermatan sulphate and a high value for heparan sulphate: $83 \%$ and $129 \%$ of chondroitin-4-sulphate respectively (22). Because of this known difference in uronic acid values for the respective polysaccharides, the urinary glycosaminoglycan content in this report was also estimated by the orcinol and electrophoretic methods (tab. 2 and 3). The values of total glycosaminoglycan content estimated by electrophoresis (tab. 3) are lower than those obtained by the carbazole and orcinol methods (tab. 2). Heparan sulphate in urine may result in a higher recorded value for glycosaminoglycans by the carbazole method. In the orcinol reaction iduronic acid gives about $15 \%$ higher colour yield than glucuronic acid (8). In addition to glucuronic acid, heparan sulphate also contains iduronic acid, and this may be the reason for the higher values obtained in the orcinol reaction. The percentage of glucosamine in the total hexosamine corresponded to the percentage of heparan sulphate in the total glycosaminoglycans estimated by electrophoresis. Therefore we can state that amount of polysaccharides estimated by electrophoresis was closer to the real values than those estimated by the carbazole and orcinol methods. Also the amounts of urinary chondroitin sulphate, based on both electrophoresis and enzymatic analysis, agreed well with each other. The sum of unsaturated disaccharides calculated by the enzymatic method and the amount of chondroitin sulphate fraction estimated by electrophoresis are not significantly different. The amounts of disaccharide subunits derived from urinary glycosaminoglycans after chondroitinase treatment were approximately $11.5 \mu \mathrm{mol}$ per day in normal urine. This value was within range of the amount reported previously by Taniguchi $(10 \mu \mathrm{mol}$ per day) (22). The molar ratio of chondroitin-4-sulphate to chondroitin-6-sulphate obtained in this study was $2.3: 1$, indicating the predominance of chondroitin-4-sulphate in urine chondroitin sulphate isomers. This is consistent with Taniguchi's findings (22), but contrary to the results of Murata et al., which indicated the predominance of chondroitin-6-sulphate in human urine (19). Although the changes in urine glycosaminoglycans in several endocrinopathies has been investigated (31), to our knowledge no information on the content and composition of urinary glycosaminoglycans in hypothyroidism has hitherto been reported. It is therefore of interest to investigate any differences that might exist in terms of glycosaminoglycan excretion between hypothyroidism and healthy subjects. Analysis of our results shows that significant differences exist between the mean excretion of glycosaminoglycans in normal and hypothyroidism subjects, either as total glycosaminoglycans or as its separate components. We found that the concentration of hexuronic acid glycosaminoglycans in the urine of hypothyroidism patients was $41 \%$ higher than in healthy subjects. Heparan sulphate and chondroitin-4/6-sulphate levels were $114 \%$ and $42 \%$ higher than in a the control group. Chondroitin-4-sulphate and chondroitin-6-sulphate increased significantly by $31 \%$ and by $41 \%$ respectively. The average molar ratio of chondroitin-4-sulphate to chondroitin-6-sulphate was $2.1: 1.0$. The percentage 
distribution of chondroitin-4-sulphate, dermatan sulphate, chondroitin-6-sulphate and non sulphated chondroitin sulphate in the total chondroitin sulphate did not change in the two examined groups.

The urinary glycosaminoglycans are the final degradation products of the proteoglycans found in the macromolecular matrix of connective tissue. Therefore the changes observed at the level of the excreted glycosaminoglycans may reflect the altered metabolism of connective tissue. Several authors have reported an increased content of glycosaminoglycans in the dermis (5), human aorta wall (32) and other tissues (6) of patients with hypothyroidism. In our previous study we observed a decrease of hyaluronidase activity in the serum of patients with hypothyroidism (33). The activity of hyaluronidase in the liver, muscle and skin tissues of animals with experimental hypothyroidism was investigated by Martino et al. (34). The

\section{References}

1. Stuhlsatz, H. \& Greiling, H. (1982) in "Glycosaminoglycans and Proteoglycans in Physiological Processes of Body Systems" (Varma, R., ed.) pp. 276-289, Karger, Basel.

2. Greiling, H. (1974) in "Clinical Biochemistry, Principles and Methods" (Curtius, H. C. \& Roth, M., eds.) pp. 944971, De Gruyter, Berlin.

3. Lamberg, S. \& Stoolmiller, A. (1974) J. Invest. Derm. 63, $433-449$.

4. Watson, E. \& Pearce, R. (1949) Am. J. Clin. Pathol. 19, $442-446$.

5. Varma, R. S. \& Varma, R. (1982) in "Glycosaminoglycans and Proteoglycans in Physiological and Pathological Processes of Body Systems" (Varma, R. S. \& Varma, R., eds.) pp. $151-164$, Karger, Basel.

6. Parving, H. (1982) Clin. Endocrinol. 16, 207-210.

7. Annino, J. S. \& Giese, R. W. (1976) in "Clinical Chemistry Principles and Procedures", 4th edn (Brown \& Co., eds.) pp. 173-174, Boston.

8. Roden, L., Baker, J., Cifonelli, J. A. \& Mathews, M. B. (1972) in "Methods in Enzymology" (Victor Ginsburg, eds.) pp. 73-140, Academic Press, New York-London.

9. Bitter, T. \& Muir, H. (1962) Anal. Biochem. 4, 330-334.

10. Mossman, J. \& Patrick, A. (1982) Prenatal Diagnosis 2, $169-186$

11. Saito, H., Yamagata, T. \& Suzuki, S. (1968) J. Biol. Chem. 243, 1536-1542

12. Yosizawa, Z., Ototani, N. \& Satake, S. (1983) Anal. Biochem. 128, 250-256.

13. Murata, K. \& Takeda, H. (1980) Clin. Chim. Acta 108, 49-59.

14. Taniguchi, N., Moriya, M. \& Nanba, J. (1974) Clin. Chim Acta 50, 319-328.

15. Hronowski, L. \& Anastassiades, T. (1979) Anal. Biochem. $93,60-72$. activity of this enzyme was reduced to the $40-50 \%$ of normal. Hyaluronidase degrades hyaluronic acid, chondroitin-4-sulphate and chondroitin-6-sulphate, so the reduced activity of this endoglycosidase may be one of the reasons leading to the accumulation of the respective types of glycosaminoglycans in tissues and their high excretion with urine. As some authors suggested, myxoedematous oedema, loss of hair, hoarseness and impaired wound healing may all be due to the quantitative and qualitative changes in glycosaminoglycans of the mesenchyme (31). Further investigations are needed to ascertain the mechanism of these thyroid hormone effects on glycosaminoglycan metabolism.

\section{Acknowledgement}

I wish to thank Professor A. L. Horwitz, Department of Pediatrics, University of Chicago for the generous gift of heparan sulphate.
16. Brown, A. (1946) Arch. Biochem. 11, 269-278.

17. Blumenkrantz, N. \& Asboe-Hansen, G. (1976) Clin. Biochem. 9, 269-274.

18. Wagner, W. (1979) Anal. Biochem. 94, 394-396.

19. Murata, K., Ishikawa, T. \& Oshima, Y. (1970) Clin. Chim. Acta 28, 213-222.

20. Nagatsuka, Y., Sato, K., Ototani, N. \& Yosizawa, Z. (1980) Tohoku J. Exp. Med. 132, 159-171.

21. Humbel, R. (1975) Helv. Paediatr. Acta 30, 191-200.

22. Taniguchi, N. \& Koizumi, S. (1975) Biochem. Med. 14, $241-249$.

23. Lindner, J. (1981) Res. Mol. Biol. 10, 186-219.

24. Lindner, J. \& Grasedyck, K. (1982) Arzneim.-Forsch. Drug. Res. 32 (II), 1383-1396.

25. Pennock, C. A. et al. (1973) Acta Paediat. Scand. 62, 481 491.

26. Yokoi, T., Uozaki, T., Kasei, M. \& Sato, T. (1981) Clin. Chim. Acta 116, 153-160.

27. Goldberg, J. \& Cotlier, E. (1972) Clin. Chim. Acta 41, $19-27$.

28. Nanto-Salonen, K., Larjava, H., Aalto, M. \& Kivimaki, T. (1985) Clin. Chim. Acta 146, 111-118.

29. Varma, R. S., Varma, R., Allen, W. \& Wardi, A. (1974) Biochem. Med. 11, 358-369.

30. Bowness, J. \& Parkinson, D. (1983) Clin. Biochem. 16, 200-201.

31. Likar, I., Robinson, R. \& Likar, L. (1982) in "Glycosaminoglycans and Proteoglycans in Physiological and Pathological Processes of Body Systems" (Varma, R. S. \& Varma, R., eds.) pp. 412-439, Karger, Basel.

32. Jozsa, J. \& Szederkenyi, G. (1966) Endokrinologie 50 , $116-122$.

33. Wład, H., Suszka, B., Łącka, K. \& Chmiel, J. (1985) Endokr. Pol. 36, 215-219.

34. De Martino, G. \& Goldberg, A. (1981) Enzyme 26, $1-7$.
Hanna Wład

Department of Veterinary Medical Chemistry Swedish University of Agricultural Sciences

The Biomedical Center

Box 575

S-751 23 Uppsala 